\title{
Colonic mucosal bridging in ulcerative colitis
}

\author{
Gaurav Gupta • Sandeep Nijhawan • \\ Subhash Chander • Amit Mathur • Subhash Nepalia
}

Published online: 2 February 2012

(C) Indian Society of Gastroenterology 2012

A 55-year-old-man, who had idiopathic ulcerative colitis (IUC) for 13 years, presented with ill-defined left-sided lower abdominal pain. He was on 5-aminosalicycilates and was in remission. He previously had several episodes of severe exacerbation of IUC requiring intravenous steroids. His complete blood count, liver and renal biochemistry were normal. ESR was $10 \mathrm{~mm} / \mathrm{h}$ and C-reactive protein was negative. Colonoscopy showed loss of vascular pattern and erythema without friability till the splenic flexure. In the rectum, there was extensive mucosal regeneration forming mucosal bridges and giving 'Swiss cheese' appearance (Fig. 1). The patient was given symptomatic treatment and reassurance.

Mucosal bridging (MB) is characterized by bridging of two parts of lumen by regenerating mucosal tissue. It has been reported in colon, esophagus and stomach following inflammatory events. Colonic MB is an uncommon finding in IBD, and only few cases have been reported [1]. Pathogenesis of MB is possibly related to undermining of mucosa by ulceration followed by healing with re-epithelization of mucosal undersurface and formation of mucosal tube that is attached to each end to the non-ulcerated wall [2]. Alternatively, the free end of inflammation polyp can attach to the mucosa and form MB. On microscopy MB is characterized by chronic inflammation. MB persist even after resolution of basic dis-

G. Gupta $\cdot$ S. Nijhawan $(\bowtie) \cdot$ S. Chander $\cdot$ A. Mathur $\cdot$ S. Nepalia Department of Gastroenterology, S M S Hospital,

Jaipur, Rajasthan, India

e-mail: dr_nijhawan@yahoo.com

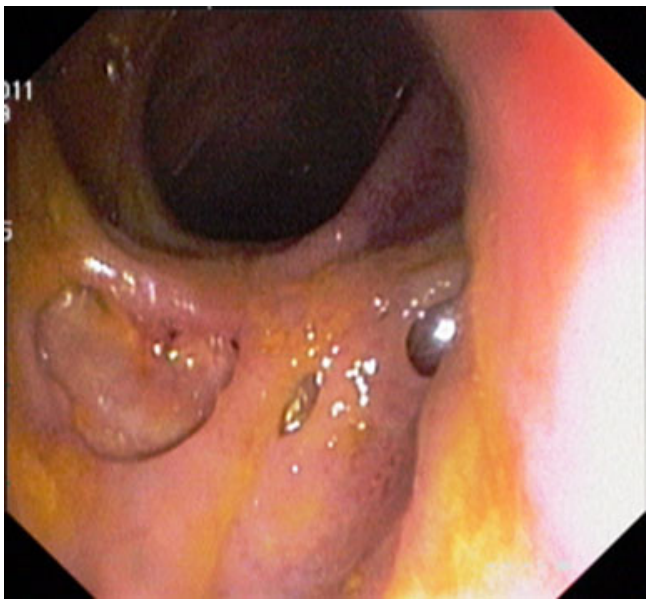

Fig. 1 Colonic mucosal bridging giving Swisss cheese appearance

ease. They carry no malignant potential [3]. Apart from IUC they can be found in ischemic colitis, infective colitis and tuberculosis of colon.

\section{References}

1. Van Moerkercke W, Deboever G, Lambrecht G, Hertveldt K. Severe bridging fibrosis of the colon in a man with inflammatory bowel disease. Endoscopy. 2007;39 Suppl 1:E294.

2. Waye JD. Endoscopy in inflammatory bowel disease. Clin Gastroenterol. 1980;9:279-96.

3. Butcher GP. Lower Gastrointestinal Bleeding: Gastroenterology: An Illustrated Colored Text. London, Churchill Livingstone, 2003; pp. $70-71$. 